DOI: $10.20472 /$ IAC.2019.049.025

\title{
JENS KRISTENSEN
}

University of Copenhagen, Denmark

\section{VALIDATION OF THE DANISH BIRTH REGISTRATION}

\begin{abstract}
:
We assessed validity and reliability of data on four serious pregnancy complications and gestational age in two national registers, the Medical Birth Register (MBR) and the National Register of Hospital Discharges (NRHD). From a cohort of all women in Denmark who gave birth to their first and second singleton infant in 1982-1987, a review was made of a selected sample of 1662 medical records. Regarding registration of pregnancy complications, there was good agreement (kappa above 0.6) between medical records and the registers, and between the registers. However, there was a tendency toward understatement evidenced by low sensitivity of three of four pregnancy complications. The level of agreement $(43 \%)$ for length of gestation was disappointing. The number of systematic and nonsystematic errors indicate that there was about $52 \%$ more singleton preterm deliveries in Denmark in 1982 than previously reported (6.9\% instead of $4.5 \%)$ ). It is concluded that the validity of the Danish birth registers should be improved by explicit definitions, increased use of raw data, and data collection by motivated professionals at birth.
\end{abstract}

\section{Keywords:}

Epidemiologi, preterm, registerstudy 